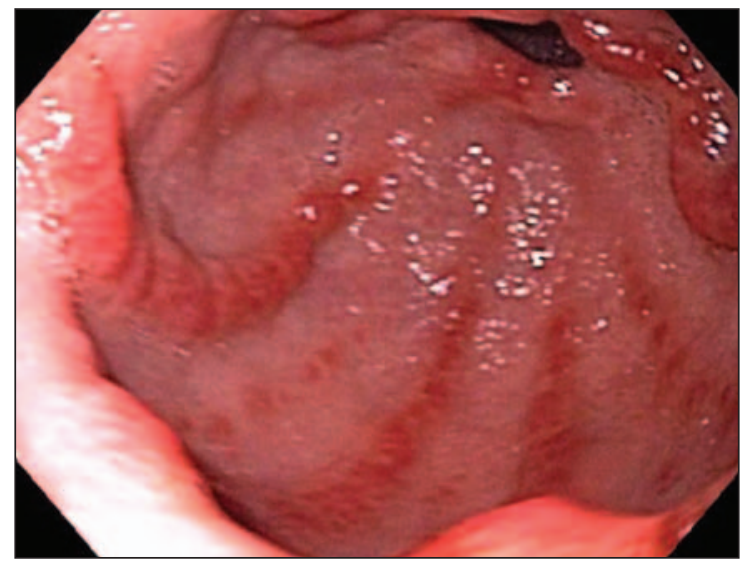

Figure 1: Photograph of gastric antral vascular ectasias (watermelon stomach) taken during endoscopy performed on a 65-year-old man.

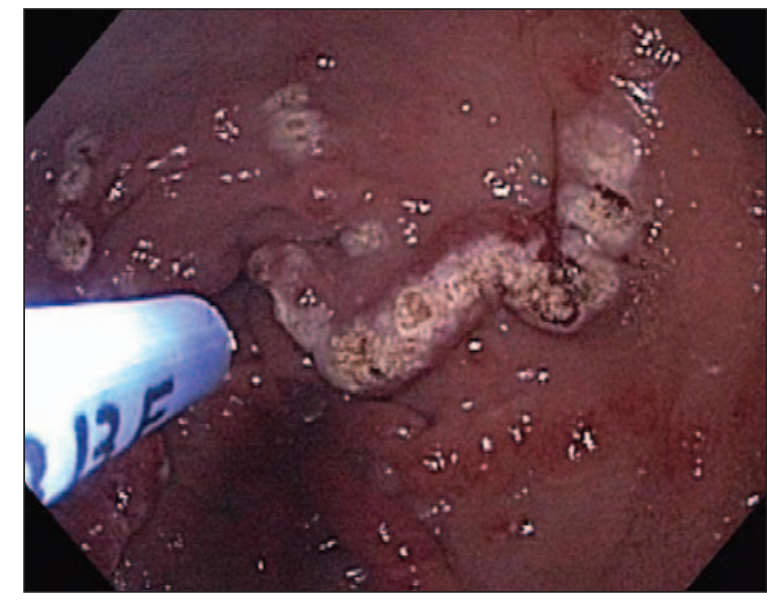

Figure 2: Argon plasma coagulation of watermelon stomach.

\title{
Watermelon stomach
}

$\mathrm{A}$ 65-year-old man with diffuse systemic sclerosis presented with severe anemia (hemoglobin $50 \mathrm{~g} / \mathrm{L}$ ) and heme in his stool. He had been taking $30 \mathrm{mg}$ of lansoprazole daily for 5 months for symptomatic acid reflux disease. He received 4 units of packed red blood cells. Esophagogastroduodenoscopy revealed gastric antral vascular ectasias (Figure 1), also known as watermelon stomach. A biopsy of the antrum showed loss of epithelial mucin, hypocellular lamina propria, dilated capillary vessels and fibrin thrombi. The vascular ectasias were treated by endoscopic argon plasma coagulation (Figure 2). A total of 3 sessions were performed, 1 per month for 3 months, to ensure complete eradication. The patient's hemoglobin level stabilized at $115 \mathrm{~g} / \mathrm{L}$ and no additional transfusions were required. He was advised to have an annual esophagogastroduodenoscopy and further coagulation treatments if the ectasias recur.

Watermelon stomach is named for the characteristic longitudinal red columns radiating to the pylorus (Figure 1), visible by endoscopy. ${ }^{1}$ The condition can occur in patients with $\overrightarrow{0}$ systemic sclerosis, portal hypertension and chronic renal failure. ${ }^{2}$ Submucosal ectatic vessels can erode through the gastric mucosa, leading to chronic loss of blood and substantial iron deficiency anemia. Watermelon stomach is believed to be one of the manifestations of the widespread vasculopathy associated with scleroderma. Histology results show dilated, thrombosed capillaries in the lamina propria and reactive fibromuscular hyperplasia. Conventional therapies for acid-peptic disease are not effective; however, argon plasma coagulation is often successful and is the treatment of choice. ${ }^{2}$
Clinical images are chosen because they are particularly intriguing, classic or dramatic. Submissions of clear, appropriately labelled high-resolution images must be accompanied by a figure caption and the patient's written consent for publication. A brief explanation (300 words maximum) of the educational significance of the images with minimal references is required.

\section{Soumya Chatterjee MD MS}

Cleveland Clinic Lerner College of Medicine of Case Western Reserve University

Department of Rheumatic and

Immunologic Diseases

Cleveland Clinic

Cleveland, Ohio

\section{REFERENCES}

1. Jabbari M, Cherry R, Lough JO, et al. Gastric antral vascular ectasia: the watermelon stomach. Gastroenterology 1984;87:1165-70

2. Novitsky YW, Kercher KW, Czerniach DR, et al. Watermelon stomach: pathophysiology, diagnosis, and management. J Gastrointest Surg 2003;7:652-61 